here, but we would underline the very high quality of the speakers, of the contributions presented and of the discussions which followed them. This seminar may be considered as a great success in the dissemination of knowledge of international humanitarian law among university and government circles in Asia and the Pacific, and the Australian National University and the Australian Red Cross deserve thanks for their excellent contribution to this humanitarian work.

\title{
Meetings in New Zealand
}

The New Zealand Red Cross Society has always been very interested in the dissemination of international humanitarian law and has always been very active in this field. It had invited Mr. J.-J. Surbeck, a specialist in the dissemination of humanitarian law at the ICRC, who was going to Australia for the Asia-Pacific regional seminar, to also visit New Zealand. The Society had organized, between 2 and 5 February, in collaboration with the Victoria University of Wellington, two meetings, one in Auckland and the other in Wellington, intended for the New Zealand public and dealing with the Red Cross and international humanitarian law.

At these meetings, the members of the audience heard exposés given either by the ICRC delegate, or by the Professors K. J. Keith and R. Q. Quentin-Baxter of the Victoria University, or by representatives of the Defence Ministry and the New Zealand Red Cross. The talks were followed by lively discussions and the lecturers were asked numerous questions.

In Auckland the audience mainly consisted of active members and voluntary workers of the Red Cross, with representatives of the Civil Defence and several social and religious organizations, whereas in Wellington, the country's capital, the participants were important officials from the Defence Ministry, the Ministry for External Affairs, the Ministry for Education and from the Civil Defence, several university professors, students and jurists interested in the subjects presented.

During these two meetings, the public showed great interest and took an active part in the discussions. These events were a success, and a valuable encouragement to the organizers and lecturers. 